\title{
Publisher Correction: Prediction of malignant glioma grades using contrast-enhanced T1-weighted and T2-weighted magnetic resonance images based on a radiomic analysis
}

\author{
Takahiro Nakamoto, Wataru Takahashi, Akihiro Haga, Satoshi Takahashi, Shigeru Kiryu $\mathbb{B}$, \\ Kanabu Nawa, Takeshi Ohta, Sho Ozaki, Yuki Nozawa, Shota Tanaka, Akitake Mukasa \& \& \\ Keiichi Nakagawa
}

Correction to: Scientific Reports https://doi.org/10.1038/s41598-019-55922-0, published online 19 December 2019

The PDF version of this Article contained errors in Table 5. In the row entitled 'Zacharaki et al. ${ }^{20}$ ', text was omitted from the 'MRI sequence' column and there were errors in the 'Feature type' and 'Filtering' columns. In addition, text was also omitted from the 'Tian et al. ${ }^{21}$ ' row in the 'MRI sequence' column.

These errors have now been corrected in the PDF version of this Article.

(c) (i) Open Access This article is licensed under a Creative Commons Attribution 4.0 International License, which permits use, sharing, adaptation, distribution and reproduction in any medium or format, as long as you give appropriate credit to the original author(s) and the source, provide a link to the Creative Commons license, and indicate if changes were made. The images or other third party material in this article are included in the article's Creative Commons license, unless indicated otherwise in a credit line to the material. If material is not included in the article's Creative Commons license and your intended use is not permitted by statutory regulation or exceeds the permitted use, you will need to obtain permission directly from the copyright holder. To view a copy of this license, visit http://creativecommons.org/licenses/by/4.0/.

(C) The Author(s) 2020 